\title{
Synchronous transnational collaborative learning: An interesting model of education to learn medicine in global perspectives
}

\author{
${ }^{1}$ Abdus Salam, ${ }^{2}$ Adibah Abdul Ghafar, ${ }^{3}$ Hasniah Abd Latif, ${ }^{4}$ Harlina Halizah Siraj, ${ }^{5}$ Zaleha Abdullah Mahdy, \\ ${ }^{6}$ Syed Zulkifli Syed Zakaria, ${ }^{7}$ Nabishah Mohamad, ${ }^{8}$ Raymond Azman Ali
}

\begin{abstract}
${ }^{1,4}$ Associate Professor, ${ }^{7}$ Professor and Head, Medical Education Department; ${ }^{2}$ Lecturer, ${ }^{3}$ Associate Professor, Paediatric Department; 'Professor, Obstetrics and Gynaecology Department and Deputy Dean, Undergraduate Studies and Community Relations; ${ }^{6}$ Professor, Paediatric Department and Deputy Dean, Human Resource and Development; ${ }^{8}$ Professor, Medicine Department and Dean and Director Faculty of Medicine; Universiti Kebangsaan Malaysia (UKM) Medical Centre, Kuala Lumpur, Malaysia.
\end{abstract}

\begin{abstract}
There is a significant gap between teaching and use of interesting technological resources by most of the faculties in medical schools around the globe. The objective of this paper is to highlight a Malaysian medical school's experience on the use of a Synchronous Transnational Collaborative Learning (STCL) methodology using MedEdWorld - a technological resource of medical education, based at Dundee University, UK. A cross sectional study was carried out on 11 year-4 students and one facilitator of University Kebangsaan Malaysia (UKM) Medical Centre who participated in MedEdWorld's STCL topic 'Yellow Newborn Infant: Normal or abnormal, that is the question' held on 24 March 2010 at 0800 hrs GMT. Other participating institutions were from Romania, Finland, Taiwan and Great Britain. The topic was delivered by a consultant from Dundee University, which lasted for one hour. At the end of the STCL presentation, a questionnaire was administered to all of the UKM Medical Centre's participants to investigate their experience. The participants' experiences were very positive and they loved it. The STCL was an interesting way to learn medicine in global perspectives, live and in the virtual presence of those from other international institutions. Medical schools should be promising to adopt STCL in order to promote medical education in an interesting way. This paper offers other medical schools, especially of the South East Asian Region, a window to promote further development of medical education and practice.
\end{abstract}

Keywords: Collaborative learning, Medicine, STLC, MedEdWorld, Global perspectives.

\section{Introduction}

Education encompasses both teaching and learning. There exists a significant gap between teaching and use of available innovative technological resources by most of the faculties in medical schools around the globe. ${ }^{1}$ Education in general and medical education in particular, is changing within the large scale transition into the $21^{\text {st }}$ century. ${ }^{2,3}$ Educational institutions now use technological platforms for collaborative learning as a process of adopting changes in medical schools. Synchronous Transnational Collaborative Learning (STCL) is an opportunity for medical schools around the world to offer their students to join and elicit different perspectives on aspects of a global topic using such a technological platform offered by MedEdWorld. MedEdWorld is an international online collaborative learning network, initiated by the Association of Medical Education in Europe (AMEE), based at Dundee University, a leading world-renowned medical education

\section{Practice points}

- Online collaborative learning requires careful planning and coordination

- A supportive person who can be contacted is very much essential.

- Participants should be trained to use software and technology.

- The mindset of both facilitators and students to accept technology is necessary.

- Intradepartmental, interdepartmental and full management support is crucial.

centre. It is aimed at medical schools, students, teachers, researchers, curriculum developers and educational managers around the world to share ideas and expertise through its various approaches and assist all concerned to

Correspondence: Dr Abdus Salam, Associate Professor, Medical Education Department, Faculty of Medicine, UKM Medical Centre, Jalan Yaacob Latif, Bandar Tun Razak, Cheras, 56000 Kuala Lumpur, Malaysia. E-mail: salam@ppukm.ukm.my, salabdus@gmail.com 
keep up-to-date with developments in medical education through access to its various resources. STCL is one of the approaches of MedEdWorld powered by the Wimba software. To share resources and take part in MedEdWorld events, individual student, teacher or institution has to enroll as member through its website http:// www.mededworld.org/. Participation of students in any STCL events is free of charge. Institutional interest in such a network is an opportunity for its staff to internationalize institutes' contribution to the global community as well as keep staff updated with latest development in education.

The UKM Medical Centre has been enrolled as a partner institution of MedEdWorld through its premier membership to avail facilities offered by MedEdWorld and also internationalization of a national university, which is one of its major aims. As such the UKM Medical Centre is a regular participant of MedEdWorld events such as STCLs and Webinars. STCLs are designed mainly for student development while webinars are designed for faculty development. The objective of this paper is to outline the STCL methodology and perceptions of the UKM Medical Centres' participants on STCL aimed to offer other medical schools a window to promote further development of medical education globally.

\section{Methodology}

It was a questionnaire survey, cross sectional in nature, carried out among a group of students of the UKM Medical Centre who participated in a one hour MedEdWorld's STCL event on a pediatric problem 'Yellow newborn infant: Normal or abnormal that is the question' held on 24 March 2010 at 08 hrs GMT. The other institutions around the world that represented their country to the global medical educational community by participating in this STCL with a respective group of their students and a facilitator were from Romania, Finland, Taiwan and Great Britain. The population of this study was medical students in their clinical years. The sample of this study was restricted to 11 medical students of year-4 and one facilitator from the Child Health Department of the UKM Medical Centre who voluntarily participated in this STCL. As such convenient sampling technique was applied to decide the sample in this study. The STCL topic was presented by an expert from Ninewells Hospital and Medical School, University of Dundee, United Kingdom utilizing MedEdWorld. All the participants of the UKM Medical Centre were provided with computers connected to the internet, a webcam and a headset. During the presentation, all participants viewed the power point slides on the topic, heard and saw the presenters' audio-video relay and shared ideas by responding and asking questions through text messages and webcam.

MedEdWorld used the Wimba platform, the classroom of which was made up of a number of panels. The panels contained various types of media where there were options such as 'text chat', 'talk button' 'hand raise', 'yes/no' options etc. through which Wimba offered a collaborative, interactive learning experience that constantly evolved and kept everyone engaged like never before, which was what the platform was all about. It was suggested that participants access a STCL session 10-15 minutes in advance to check the connection. Well before the scheduled STCL session/virtual class, participants run the Wimba Classroom Setup Wizard using a link which was supplied by the host i.e. MedEdWorld. The Setup Wizard checked the computer guided through a series of tests for 'popup blockers', and presence of supportive browsers such as 'Java', 'Signed Applet', 'Text Chat', 'Playback' and 'Recording' to ensure that the computer was compatible to perform all those functions. It was also advised to contact the host through email if there were any problems in running the Wizard. There were no problems in running the wizard. Actually, the UKMMC participants used their computer lab with guidance of lab persons. The Wizard took a few minutes to complete the test; the test actually depends on the speed of individual computers and Internet connections. The connection of headsets or headphones, microphones and web cams were checked to make sure that participants could speak to and view other participants during the STCL. To access the STCL room, participants had to launch the room link for the specific STCL which was supplied by the host earlier.

The Room ID was already entered by host. To ensure that the presenter and the host could identify the participants and their country, participants logged into the system by their name followed by an underscore prefixed with the 2 code letters supplied by the host for the participants' country. For example, a Malaysian student participant named Hazwan logged in by his name as MY_Hazwan. A facilitator participant added $\mathrm{F}$ with an underscore before their name followed by an underscore prefixed by the 2 code letters for their country, e.g. a facilitator named Sahin was from Malaysia, logged in as MY_F_Sahin. The identification letters used as prefixes were provided by the host for participants' countries. Once participants entered in the classroom they noticed a Welcome screen with the title of the STCL seminar. Participants' names were displayed in the list of people. Participants who had webcams tested it by clicking on the camera icon in the media bar of the classroom so that their picture appeared when asked a question.

On clicking the camera icon, a moveable video frame appeared. A closed black and white eye icon was then opened by clicking on it. This led to a change of color which was an indication that participants can transmit video. The middle preview button on video frame was also turned orange and an image of what the recipient sees appeared in the bottom right hand corner of the video frame. Clicking on the middle button hid the preview image. The first button should remain orange. The video frame can moved and resized. The way the system worked was that video followed Voice, i.e. audio triggered video. There were three bars 
on the left media bar indicating the quality of the internet connection. A green hat on all three bars indicated a great connection; an orange hat on top of the first or second bar indicated an adequate connection; a red hat on top of the first bar indicated poor connection. If all bars were gray, this indicated that the transmission had been disconnected. The 'Talk' button initiated microphone and video broadcast. When presenter invited any participant to speak, the participants pressed and held the 'talk' button which turned orange during talk. Participant released the talk button when they stopped talking. It was important to release the talk button when not talking to avoid noise. The presenters' picture was the default picture during the session; if the presenter asked any participants to speak, the participants' picture replaced that of the presenter. There was a text chat area, where the participants also responded to questions by typing the responses and sent them by hitting the enter key. The responses were preceded by the responders' name and were shown to all participants. The name of all the participants logged into the STCL session appeared in alphabetical order with the presenter at the top in the participant area. It was also from this area that the participant used icons to respond to the presenter. Respond icons were 'Yes' or 'No' to a question by clicking on the 'tick' or 'cross'. The responses were indicated besides participants' name. There was also a 'raised hand' icon, participants who wanted to ask a question, clicked that 'raised hand' icon and a number was appeared next to that participants' name, which was an indication to the presenter that the participant wished to respond a question. The participant had spoken, when chosen to speak. After the presentation ended, participants exited the classroom by clicked on the 'Exit' button.

At the end of the presentation or when participants left the classroom, a questionnaire was administered by the medical education department of the UKM Medical Centre to investigate the perception of the UKM participants' experience on the STCL. The questionnaire was prepared based on literatures review regarding different attributes of STCL which was validated by a similar group of UKM medical students earlier. Major attributes of the STCL used in the questionnaire included opportunities to: 'elicit different perspectives on a topic', 'participate in a live transnational presentation', 'internationalize individual/ institutes' contribution to the global community', 'collaborate in further development of medical education', 'stimulate technological development beneficial to society', 'encourage clinical reasoning and problemsolving', 'comment comfortably through Wimba', 'understand a topic putting ideas together', and 'broaden knowledge'. A rating scale was used against each of these attributes, which were 'strongly agree' (SA), 'agree' (A), 'undecided' (U), 'disagree' (D) and 'strongly disagree' (SD). Respondents were also requested to put their comments on their experience on STCL, if they wished to like. The data were then compiled and analyzed using SPSS version 15 .

\section{Results}

Table 1 showed the distribution of respondents on various features of STCL. Almost all the features of STCL were rated as 'strongly agree' and 'agree' by the participants.

Table 1: Distribution of respondents on various features of STCL

\begin{tabular}{|c|c|c|c|c|c|}
\hline Features of STCL & SA & $\mathbf{A}$ & $\mathbf{U}$ & $\mathbf{D}$ & SD \\
\hline STCL is an effective way to elicit different perspectives on aspect of a topic & $6(50 \%)$ & $6(50 \%)$ & 0 & 0 & 0 \\
\hline $\begin{array}{l}\text { STCL provides an opportunities to participate live in a transnational } \\
\text { presentation }\end{array}$ & $3(25 \%)$ & $9(75 \%)$ & 0 & 0 & 0 \\
\hline $\begin{array}{l}\text { STCL offers opportunities to internationalize institutes contribution to } \\
\text { the global community }\end{array}$ & $6(50 \%)$ & $6(50 \%)$ & 0 & 0 & 0 \\
\hline STCL collaborates in further development of medical education & $7(58 \%)$ & $5(42 \%)$ & 0 & 0 & 0 \\
\hline STCL stimulates the development of technologies beneficial to society & $6(50 \%)$ & $6(50 \%)$ & 0 & 0 & 0 \\
\hline STCL encouraged clinical reasoning and problem solving & $5(42 \%)$ & $7(58 \%)$ & 0 & 0 & 0 \\
\hline It was comfortable to contribute comments through Wimba platform & $6(50 \%)$ & $6(50 \%)$ & 0 & 0 & 0 \\
\hline STCL provides opportunities to understand a topic putting ideas together & $6(50 \%)$ & $6(50 \%)$ & 0 & 0 & 0 \\
\hline STCL was a rewording experience & $5(42 \%)$ & $7(58 \%)$ & 0 & 0 & 0 \\
\hline STCL task enabled broaden knowledge & $3(25 \%)$ & $6(50 \%)$ & $3(25 \%)$ & 0 & 0 \\
\hline
\end{tabular}

Keys: STCL- Synchronous Transnational Collaborative Learning, SA- Strongly agree, A- Agree, U- Undecided, D- Disagree, SA-Strongly disagree 
Table 2 shows the distribution of open comments on the STCL by the respondents. Of a total of 12 participants including the facilitator, 11 had given open comments giving a response rate of $91.67 \%$. Participants' comments on the STCL were positive, as shown in Table 2.

\section{Discussion}

Synchronous Transnational Collaborative Learning is an aspect of MedEdWorlds' enhanced technological development using webcam, headset and collaborative software 'Wimba' with internet connection. All the features of STCL were rated positively as strongly agree and agree by all the respondents except only one feature, where $25 \%$ respondents were unsure about whether STCL tasks broadened their knowledge or not (Table 1). As such this study indicated that STCL was an effective way to elicit different perspectives on aspect of a global problem and able to collaborates in further development of medical education.

Regarding online collaboration, we find similarities where $\mathrm{Fyfe}^{4}$ pointed out that if a participant cannot effectively use the software and/or technology then problems might arise. So it is important for both students and facilitators to become familiar with the software and technology available for the course who involved in online learning and this can be achieved by appropriate training to use the technology.

Respondents commented on STCL 'Yellow newborn infant: Normal or abnormal that is the question' in a very positive way, although the sound quality was interrupted occasionally due to a slow internet speed (Table 2). Respondents identified that the STCL was an interesting way to learn medicine because it was interactive, as well as it was like chatting and learning both at the same time and it enabled respondents to know other participants from other countries' of same field (Table 2). This finding correlates with the findings of earlier studies where it was mentioned that STCL was an effective way to elicit different perspectives on aspects of a global topic. ${ }^{5}$

STCL is a computer-assisted innovative instructional approach in medical education. In the comments, a few students commented that sometimes sound quality was not loud enough otherwise the STCL was a good experience (Table 2). Berman et al. ${ }^{6}$ reported that although there is great interest in using computer-assisted instruction in medical education, but using computer-assisted instructional material broadly is difficult to achieve. The real challenge is in effectively using technology which requires a primary focus on educators and students rather than on the technology itself, ${ }^{6}$ which indicates that the participant should be trained adequately to use the software and technology.

A small sample size and the confinement of the study within UKM participants is the limitation of this study. As such, further large scale studies involving worldwide participants' views are recommended for more information. However, STCL was a rewarding experience and the MedEdWorld is a unique platform of collaborative learning where it offered institutions' options for their students' opportunities to join with students in schools from other countries through STCL sessions. ${ }^{7}$ Participation in STCL events was an opportunity for all participants to update with latest development in medical education. Implementing an effective global online collaborative learning networking requires a careful planning, coordination, as well as preparation of both facilitators and students, ${ }^{5,8}$ and full management support at intradepartmental, interdepartmental and institutional levels. Mindset of facilitators and students to accept technology is also an important aspect of effective online collaboration. The UKM Medical Centre is committed to raise the standard of medical education ${ }^{9}$ for which it was possible for the UKM participants to take part in a series of

Table 2: Participants' comments on STCL

'The STCL session was very useful for medical undergraduates'

'Should do more often'

'This was an interactive session, please do more'

'Good, if this can be done during our posting so that can stimulate our learning'

'This was a very interesting session and would be more appropriate to encourage students to participates during posting'

'Strongly love to learn from this presentation'

'Over all was good and just that sometimes cannot heard clearly'

'It was interesting and very helpful, indeed even better than text book and love it, but sound quality needs to be improved'

'Can do more frequent'

'The volume was not loud enough, otherwise it was a good experience'

'It was an interesting way to learn medicine because it was like chatting and learning both at the same time and it enabled us to know other people from other countries of same field' 
STCLs and other events due to its premier membership with MedEdWorld.

\section{Conclusion}

This study concluded that STCL emerged as a new, exciting way of learning medicine and sharing perspectives with people from other countries who were in the same field on a common global problem. Medical schools across the world should adopt STCL as an interesting and promising model of education aimed to promote learning medicine in global perspectives, live and in the virtual presence of those from other international institutions and thereby meet the challenges of the development of science and technology. This paper offers other medical schools, especially of the South East Asian Region, a window to promote further development of medical education and practice.

\section{References}

1. Skochelak SE. A Century of Progress in Medical Education: What about the Next 10 Years? Acad Med.2010;85:197-200.

2. Benor DE. Faculty development, teacher training and accreditation in medical education: twenty years from now. Med Teach 2000;22:503-12.

3. Salam A, Rabeya Y. Residential Field Site Training: Bangladesh Approach to Community Based Education to Develop Generic Skills in Tomorrows' Doctors. Middle East JNurs 2009; 3: 22-7.
4. Fyfe S. Collaborative learning at a distance: The Human Biology experience. In A. Herrmann \& M. M. Kulski (Eds), Flexible Futures in Tertiary Teaching. Proceedings of the 9th Annual Teaching Learning Forum, 2-4 February 2000, Perth, Curtin University of Technology. http://1sn.curtin.edu.au/tlf/ tlf2000/fyfes.html. (Accessed Dec 25, 2011).

5. Salam A, Aziz NA, Arif K, Harlina HS, Nabishah M, Norhayati M, Saim L. MedEdWorld online global collaborative learning network using Adobe Connect: An experience of Universiti Kabangsaan Malaysian Medical Centre. Med Educ Online 2009;14.

6. Berman NB, Fall LH, Chessman AW, Dell MR, Lang VJ, Leong SL, Nixon LJ, \& Smith S. A collaborative model for developing and maintaining virtual patients for medical education. Med Teach 2011;33:319-24.

7. MedEdWorld. Welcome to MedEdWorld. http://www.mededworld.org/ (Accessed Dec 25, 2011).

8. Soekartawi. Effectiveness of Collaborative Learning in Online Teaching. Malaysian Online J Instr Technol 2006;3:68-77.

9. Salam A, Norlinah MI, Mohamad AK et al. Technology Enhanced Global Online Collaborative Networking Using MedEdWorld Wimba: UKM Medical Centre's Experience. Int Med J 2011; 18:107-9. 